\title{
Rat heart T2-mapping with full coverage of the left ventricle myocardium
}

\author{
Edvin Johansson ${ }^{1 *}$, Tamsin Albery ${ }^{2}$, Malin Palmér ${ }^{2}$, Sven Månssonx ${ }^{3}$ \\ From 19th Annual SCMR Scientific Sessions \\ Los Angeles, CA, USA. 27-30 January 2016
}

\begin{abstract}
Background
MRI cardiac T2-mapping visualizes edema and has been used for tissue characterization in settings such as myocarditis and ischemia. Clinically it is typically performed via spin-echo based techniques, but preclinically, the high heart rates of rats and mice make such approaches sensitive to motion. Successful implementations instead employ T2-preparation followed by a segmented gradient-echo readout (Beyers et al. MRM 2012, Coolen et al. MRM 2014). It is argued here that when full coverage of the left ventricle myocardium (LVM) is needed, such techniques benefit from applying phase encoding in the slice direction as opposed to using a multi-slice approach.
\end{abstract}

\section{Methods}

All work was approved by the local ethical committee. At day 0, 14 rats (male Clr: CD, Sprague-Dawley, $\sim 300$ g) were subjected to sham operation (open chest surgery, non-occlusive suture in LVM). Scanning was performed at days 1, 4, and 8 , under Isoflurane anaesthesia on a Bruker BioSpec 4.7T scanner equipped with a $72 \mathrm{~mm}$ quadrature coil. T2-preparation module: non-selective $90^{\circ}-180^{\circ}-90^{\circ}$ excitation pulses with four echo times $(5,23,41,59 \mathrm{~ms})$. Readout module: 3D gradient echo with phase encoding in the slice direction, FOV $40 \times 40$ $\mathrm{mm}^{2}$, slice thickness $1.5 \mathrm{~mm}, 128 \times 126 \times 8$ matrix, FA $30^{\circ}$, TR $4.0 \mathrm{~ms}$, TE $1.5 \mathrm{~ms}$, bandwidth $50 \mathrm{kHz}, 6$ lines per segment synchronized to the systolic phase. The repetition time between segments was $\sim 2300 \mathrm{~ms}$ (minimum $2000 \mathrm{~ms}$, but depending on the respiration rate). The acquisition time was $\sim 6 \mathrm{~min} .30 \mathrm{~s}$. per echo-time. T2 maps were calculated via the method described by Pei et al. MRM 2015. Regions-of-Interests (ROIs) were manually placed in the LVM and in the back muscle.
ROI-level T2s were calculated as the harmonic mean of pixel-level T2s.

\section{Results}

T2 appeared homogeneous both in the LVM and in the back muscle (Figure 1). LVM T2 did not change over the eight-day period (Table 1) and remained fractionally higher than corresponding data in the back muscle at all-time points ( $\mathrm{p}<0.0001$, two-sided $\mathrm{t}$-test).

\section{Conclusions}

Precise T2-maps covering the full LVM were generated in sham operated rats with a signal acquisition technique earlier not used in this setting. T2 remained constant in the LV for eight days contrasting a previous report in healthy mice (Coolen et al. MRM 2014). When multislice imaging cannot be interleaved, as is the case for sequences relying on global $\mathrm{T} 2$ preparation, employing a phase encoding gradient in the slice direction is inherently a more efficient signal sampling strategy (Edelstein et al. MRM 1986). The signal-to-noise ratio (SNR) is increased by a factor $\sqrt{ } \mathrm{N}$ for a given acquisition time, where $\mathrm{N}$ is the number of slices. Alternatively, for a fixed SNR, a potential reduction in acquisition time by a factor $\mathrm{N}$ can be reached. In the present study a standard volume coil was used. Further improvements in SNR or reductions in acquisition times can be obtained by combining the proposed imaging sequence with surface coils and imaging acceleration techniques.

\footnotetext{
Authors' details

${ }^{1}$ PHB Imaging, AstraZeneca R\&D, Mölndal, Sweden. ${ }^{2}$ CVMD Cardiac Regeneration, AstraZeneca R\&D, Mölndal, Sweden. ${ }^{3}$ Department of Medical Radiation Physics, Skåne University Hospital, Lund University, Malmö, Sweden.
}

'PHB Imaging, AstraZeneca R\&D, Mölndal, Sweden

Full list of author information is available at the end of the article 


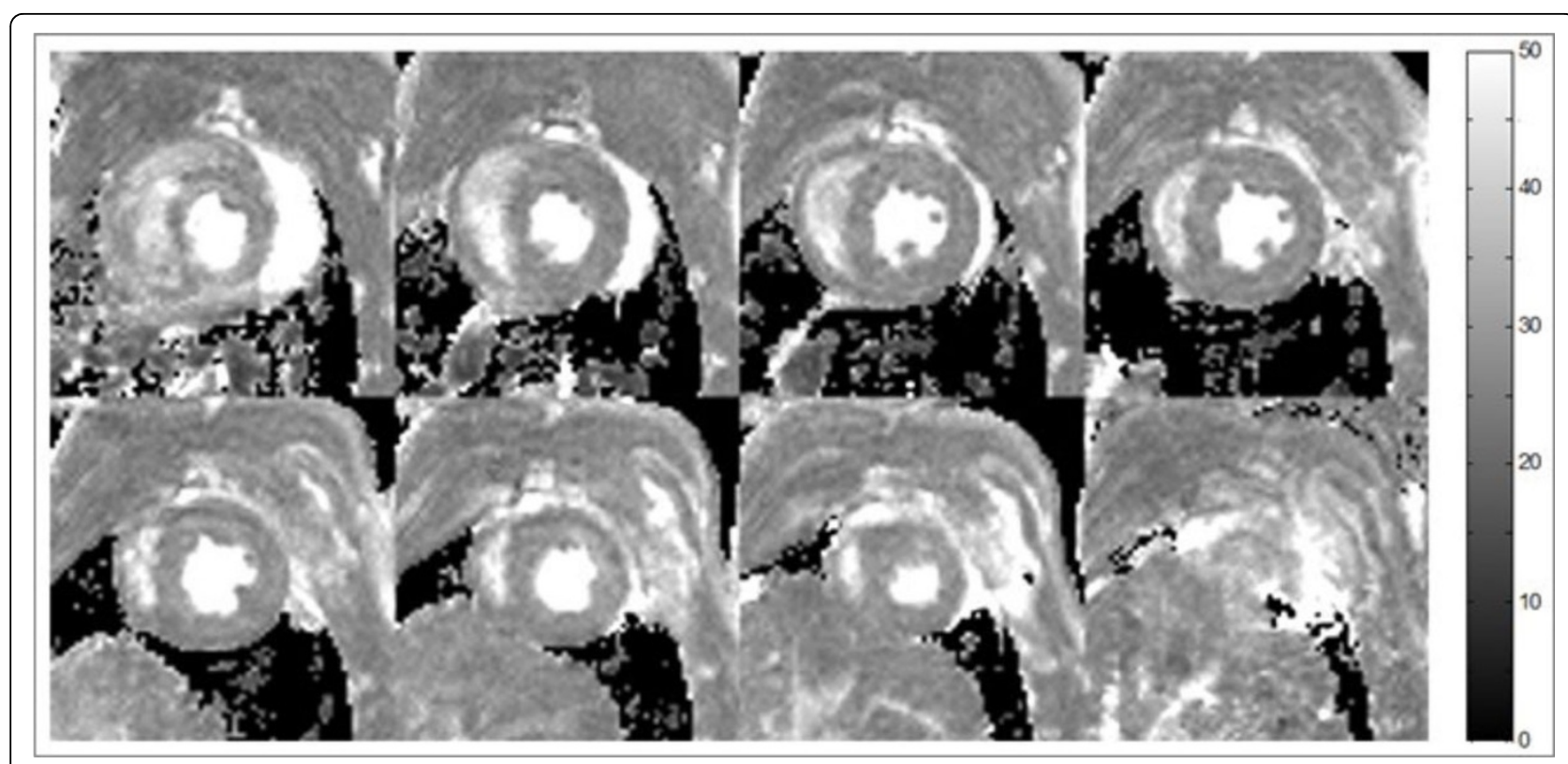

Figure 1 T2 maps covering the full extent of the rat left ventricle myocardium. Gray-scale levels express T2-values in ms. Pixels with low SNRs are shown as black.

Table $1 \mathrm{~T} 2$ in rat left ventricle myocardium (LVM) and back muscle (mean \pm standard deviation, $n=14$ ) at days 1,4 , and 8 at $4.7 T$.

\begin{tabular}{cccc}
\hline T2 & Day 1 & Day 4 & Day 8 \\
\hline Left ventricle myocardium & $29.4 \pm 1.4 \mathrm{~ms}$ & $29.1 \pm 1.3 \mathrm{~ms}$ & $29.4 \pm 0.8 \mathrm{~ms}$ \\
Back muscle & $26.5 \pm 1.6 \mathrm{~ms}$ & $26.1 \pm 1.2 \mathrm{~ms}$ & $26.3 \pm 0.8 \mathrm{~ms}$ \\
\hline
\end{tabular}

Published: 27 January 2016

doi:10.1186/1532-429X-18-S1-P49

Cite this article as: Johansson et al:: Rat heart T2-mapping with full coverage of the left ventricle myocardium. Journal of Cardiovascular Magnetic Resonance 2016 18(Suppl 1):P49.
Submit your next manuscript to BioMed Central and take full advantage of:

- Convenient online submission

- Thorough peer review

- No space constraints or color figure charges

- Immediate publication on acceptance

- Inclusion in PubMed, CAS, Scopus and Google Scholar

- Research which is freely available for redistribution 